\title{
A DECISION-SUPPORT SYSTEM FOR IMPROVING ROAD TRANSPORTATION PERFORMANCE IN GAUTENG, SOUTH AFRICA: DEVELOPING A DATA ACQUISITIONING SYSTEM
}

\author{
GEORG HEINRICH (HEINI) BACKEBERG \\ heinib@telkomsa.net \\ Department of Transport and Supply Chain Management \\ University of Johannesburg
}

\begin{abstract}
This research describes how the systems approach can be applied to implement a holistic transportation decision-support system, which will measure transportation performance at the highest level and enable decision-making with respect to possible improvements. The research starts with the creation of a framework of the process to be followed. A framework of the envisioned system with existing and new elements is then created. Furthermore, a framework for management reports is proposed. Against this background, the deliverables for a project to implement the proposed data-acquisitioning system are defined. First order indications are that such a project is feasible and affordable, and can be completed to such an extent that most of the advantages are obtainable within two years.
\end{abstract}

\section{INTRODUCTION}

According to the Gauteng Department of Public Transport, Roads and Works, "Gauteng covers $1.4 \%$ of the total surface area of South Africa but is home to $17.1 \%$ of the country's population. This represents a population density of 374.7 persons per square kilometre compared to the national average of 33.8. Gauteng also has the highest per capita income of R19 261 p.a. compared to the national average of R8 704. Gauteng contributes 37.7\% to the country's GDP and 9\% of the economy of the African continent". It has a total population of 9.1 million people. The total road network in Gauteng spans $34100 \mathrm{~km}$, of which 4888 $\mathrm{km}$ is under provincial jurisdiction. Every working day 1471100 passenger trips are carried out by taxi, 430100 by bus and 1406400 by rail (Gauteng Department of Public Transport, Roads and Works 2003, 3.2, 3.3 \& 3.8). Congestion has become a major problem in some of the metropolitan areas.

For optimisation, control and maintenance of the above transport system, integrated transportation information is needed on a regular basis. Decision-making at all levels, aimed at improving the transportation system, depends on the contents and quality of the information and the frequency at which it is updated. This study proposes a data capturing and processing model to populate a transportation decision-support framework. 
"Logistics costs make up a considerable percentage of the country's GDP (14.7\% or R180 billion). We spend more on transport than was generally expected and much more than we should" (CSIR \& Spoornet, 2004: iii). The comparable percentage in the United States is $8.5 \%$ of the GDP (Anon, 2005a: 21). "In the entire South African economy, the total throughput ... amounted to 745 million tonnes ... Transport contributed $78 \%$ to the secondary sector of the economy and 60\% to the primary sector." (Poggiolini, 2005: 17).

In order to improve the above situation, performance information is needed on a regular basis. "As South Africa grapples with new investment requirements ... policy makers experience an ever-increasing shortage of useful tools to guide decision-making and measure performance" (H Littmann, CSIR, as quoted by Anon, 2005a: 21). Such a tool "to guide decision-making and measure performance" is discussed in this study.

Decision-making at all levels, aimed at improving the transport system, depends on the contents and quality of the transportation performance information and the frequency at which it is updated. Backeberg (2005) proposes a framework for quantifying transportation performance. Backeberg uses the systems approach to develop a model for measuring the cost-effectiveness of transportation at the highest level, by combining lower level performance indicators.

The purpose of this research is to take the above study further by proposing an integrated data capturing and processing model to inform the above quantification framework and enable transportation performance measurement at all levels. The development of a traffic surveying strategy for the Gauteng Department of Public Transport, Roads and Works in 2004 is used as a case study. As this department oversees road transport only, the study will be restricted to road transport.

\section{THE IMPORTANCE OF PERFORMANCE MANAGEMENT}

Government performance (which includes transportation) became important for the South African government with the introduction of the Public Finance Management Act (PFMA) in 1999 (Act No. 1 of 1999). The Act is concerned with the efficient and effective management of state resources. The focus is not only to stay within budget, but also to obtain value for money (AFReC, 2002: ch 1). The Act compels government institutions to report on both financial and non-financial information. "The focus of the budget system consequently changed from custody of funds to effective and efficient use thereof" (AFReC, 2002: 1.9). Also at a local level, legislation "requires municipalities in South Africa to measure and report on their performance" (Swanevelder, 2005: 66).

Performance measurement is important for all three tiers or levels of government, namely national, provincial and local (or municipal). According to the PFMA, "The accounting 
officer for each department must submit to Parliament measurable objectives for each main division within the department's vote" (National Government of South Africa, 1999: Section 27 [4]). The question arises as to what these objectives should be and what to measure in order to verify improvement.

Backeberg (2005: 24) derives the ultimate aim of the government from a statement by the African National Congress National Executive Committee, that "the ANC has dedicated itself to work with all the people of our country to achieve the goal of a better life for all" (ANC National Executive Committee 2004). Rule (2004: 8) confirms that the single most important reason for voting for a certain party in 1999 was a "better life in South Africa". This is further confirmed by the Gauteng Department of Public Transport, Roads and Works (2002: 8) that refers to the aim as "Continuous transformation or improvement to create a better life for all". Backeberg (2005) uses the latter as the ultimate aim of government as a whole, and develops a high-level purpose structure for the government of which transportation forms one of the goals. He argues that transportation, normally represented by the Department of Transport (or the "Transport Branch" in Gauteng) has to contribute to this primary aim, or purpose, together with many other bodies, institutions and sectors.

The main aim or purpose of transportation is derived from the stated vision and mission of the Gauteng Department of Public Transport, Roads and Works (2003b: 5) as follows: "To cost-effectively facilitate an integrated transport system that promotes accessibility and the safe and affordable movement of people, goods and services". Six goals or applications (which have to be optimised in a combined way to achieve the above), are listed, namely road safety, road infrastructure, traffic, public transport, freight and non-motorised transport (Backeberg, 2005: 26-27).

For quantifying how cost-effectively the above applications have improved the living conditions of South Africans, a cost-effectiveness model is proposed (Backeberg, 2005: 27-29). The model displays the direct government expenditure (on each of the above six applications) on the one side and the resulting economic benefits (or costs) of each on the other. The above source suggests indicators, quantifiers and multipliers to quantify the latter, but does not elaborate on these.

\section{THE IMPORTANCE OF SYSTEMS THINKING}

Applying systems thinking or the systems approach (in contrast to the analytical approach) is fundamental to the research. Before proceeding to the development of a decision-support system, it is important to define the term "system". Mallach (1994: 72) simply defines a system as a group of interacting components with a purpose. Kast and Rosenzweig (1974: 20) add more dimensions, by defining a system as follows: "A system is an organised, 
unitary whole composed of two or more interdependent parts, components, or subsystems and delineated by identifiable boundaries from its environmental suprasystem. Systems theory ... considers interrelationships among subsystems as well as interactions between the system and its suprasystem, and also provides means of understanding synergistic aspects". Turban and Aronson (1998: 35) refer to the interactions and interconnections among subsystems as interfaces. In the latter part of the nineteenth and in the twentieth century, scientists discovered that the interactions of the solutions of disassembled parts were of greater importance than the solutions considered separately (Ackoff 1981: 14).

In the literature, elements of transportation management could be found. Greenwood and Denton (2003) describe a safety management system within the New Zealand Road Controlling Authorities. Safety management can be regarded as an element of transportation management. Poggiolini (2004: 16) proposes electronic vehicle identification (EVI) as an important enabler of transportation management. The challenge is to combine elements such as the above into an optimised whole. This can be achieved by applying systems thinking in first focusing outwards to understand the containing whole and then to explain the individual transportation elements in terms of their roles or behaviours within the containing whole (Gharajedaghi, 1999: 15). Brits, Shahia, Vorster and Barendrecht (1994: 27) state it as follows: "An improved or new system component should harmonize or be reconcilable with the system or subsystem in which it is to operate". Such a "higher order" system may be the government as a whole, with the stated aim of providing a better life for all, as described earlier. Within this context the problem statement and scope of the research will be defined in the next section.

\section{PROBLEM STATEMENT AND SCOPE OF THE RESEARCH}

In line with the outward approach of systems thinking, the overall (or broader) problem is that transportation performance (or its contribution to the economy) in Gauteng cannot be holistically determined and therefore not improved in an integrated way. To achieve this, transportation performance has to be quantified, measured and reacted upon holistically. For this, an integrated decision-support system is required. "The moment that managers start measuring performance, it will improve. As soon as performance is reported, it improves further. We know that measuring and reporting performance will save a great deal of money and improve service" (Alberta Auditor General, undated, as quoted by AFReC, September 2002: Presentation).

For a decision-support system to be effective, the following is needed:

a. A way of identifying performance indicators and quantifying them. This is addressed by Backeberg (2005), who explains the problem of fractured information elements for policy 
making. He applies systems thinking/theory to develop an integrated cost-effectiveness framework for improving policy/decision-making at top level. Detail of the above falls outside the scope of this study. The above source suggests indicators, quantifiers and multipliers to quantify the latter, but does not elaborate on these. Furthermore, the model is not validated and the value of this data, if available, may not be evident to the reader.

b. A system that captures the necessary data, processes it and presents the information in a way that will facilitate decision-making. This is the focus of the research.

c. A way of managing and maintaining the above system. This does not form part of the research.

The research focuses on (b) above by proposing an integrated system for obtaining the necessary data and transforming it into decision-supporting information. Validation of such a system with typical data falls outside the scope of this study, but it is addressed in a paper by the same author elsewhere in this publication.

Although the principles apply equally well to air, sea and rail transport, for the sake of simplicity only road transport is addressed in the research. In the context of the research the term "transportation" therefore refers to "road transportation" in the narrower sense.

\section{THE PROCESS OF DEFINING A TRANSPORTATION DECISION-SUPPORT SYSTEM}

Firstly, the process of developing a decision-support system for transportation will be explained. The process is illustrated in Figure 1 in the form of a logical flow diagram.

Figure 1 illustrates the thinking process behind this research to arrive at a holistic transportation decision-support system. Sparrius (2005: 1.10) states that the first question to be asked in the life cycle of an engineering-intensive project is: Who is the customer and what are his needs? This is illustrated in the top two left blocks in Figure 1. In this research, the "customer" of the decision-support system is regarded as the government (represented by officials at various levels), with its beneficiaries being the people of South Africa. The focus in this research is on the second last block, namely the definition of the decision-support system. The other blocks serve as inputs and outputs to the latter, and are not explicitly referred to in the research. 


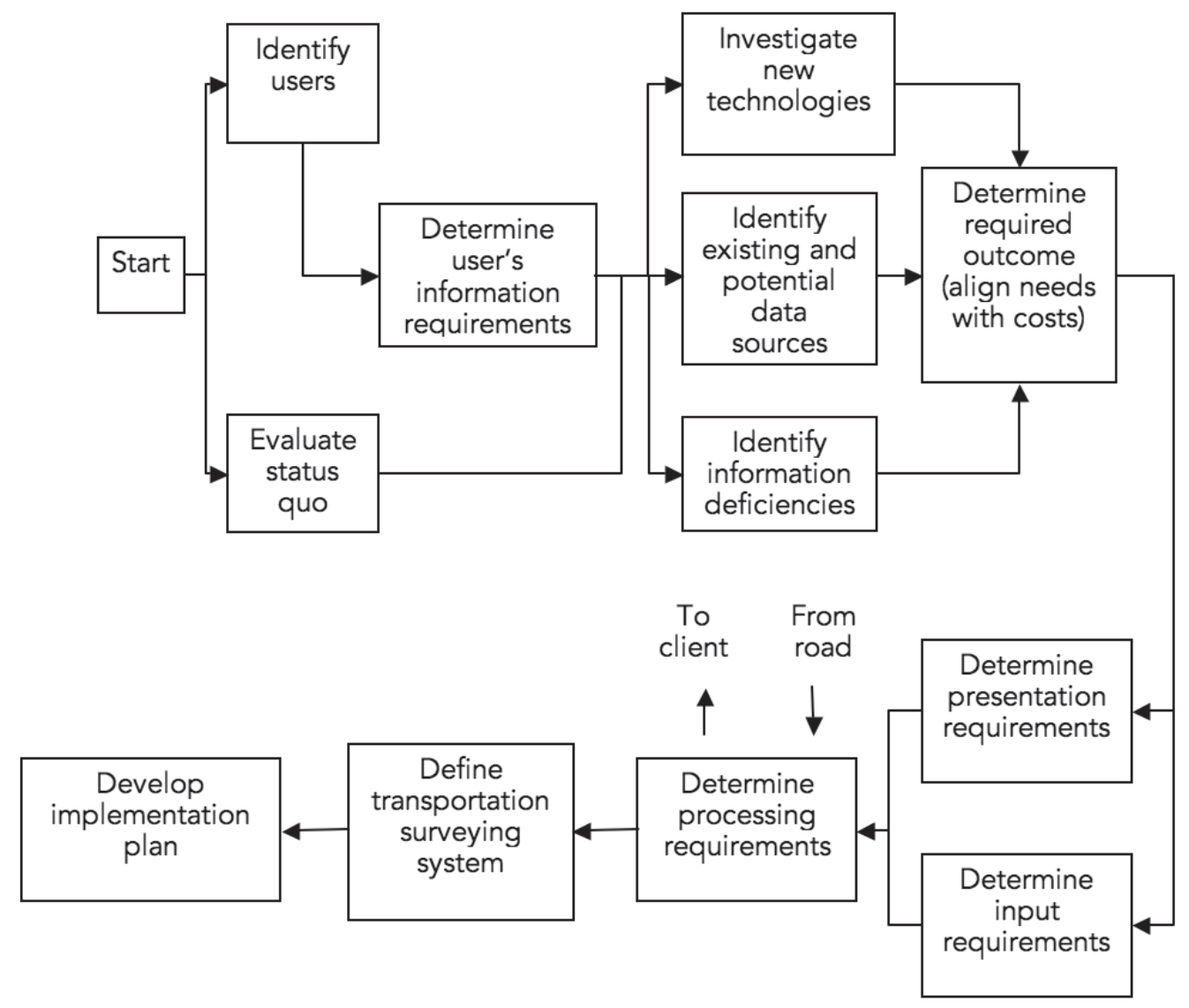

Figure 1: Logical flow diagram for defining and implementing a transportation decision-support system

\section{DEVELOPMENT OF THE TRANSPORTATION DECISION-SUPPORT SYSTEM}

In line with the systems approach, the transportation decision-support system has to be more than just a list of elements. It has to be "an organised, unitary whole", of which the interdependency of its elements is well defined - and even more important than the elements themselves. This means that even if all data sources exist, they must still be structured optimally to provide proper decision support.

For maximum affordability, the proposed decision-support system makes optimal use of existing data sources. The most cost-effective combination of data sources has to be developed. The philosophy is to integrate these data sources in such a way that maximum synergy is achieved. Various sources that are inadequate and inaccurate on their own, could provide adequate and accurate information if combined. For example, toll gates and weigh bridges can also supply daily traffic counting information, which, if combined with accident statistics, can give valuable inputs with regards to congestion, service levels and potential remedial actions.

In line with all the above, the proposed decision-support system is structured as illustrated in Figure 2. 


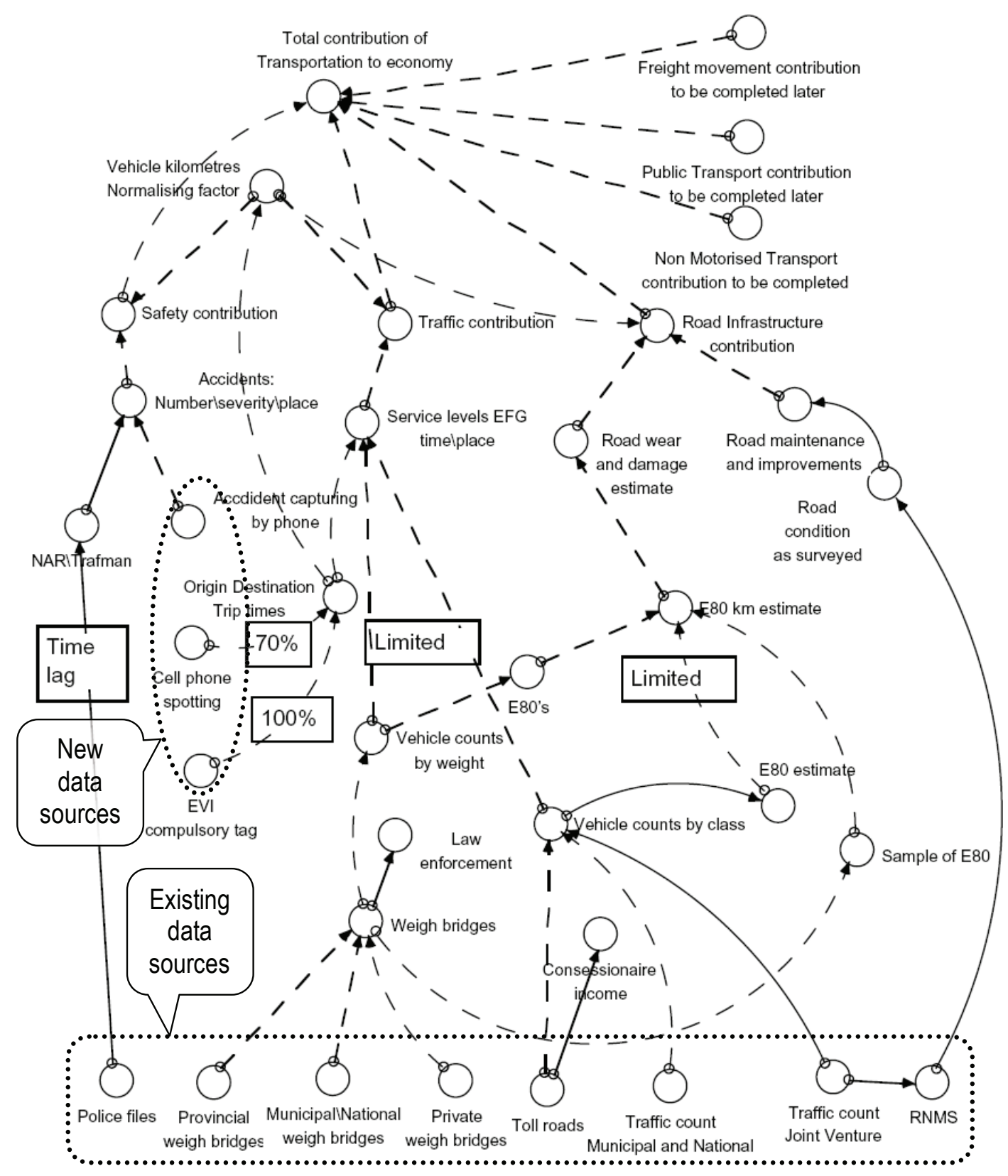

Note 1: All arrows indicate flow of information.

Note 2: Solid lines indicate existing interfaces. Broken lines indicate new / proposed interfaces.

Note 3: Data sources within the dotted oval do not exist yet. All other data sources (i.e. within the dotted square) already exist.

Figure 2: The scope of the proposed transportation decision-support system

Figure 2 shows how existing and new data sources can be used to measure the effectiveness of transportation on the roads. This will eventually lead to a total (combined) effectiveness figure at the top, which is equivalent to the total contribution of transportation to the economy. Regular feedback with respect to the above is mandated by the Public Finance Management Act (Act No. 1 of 1999) and will enable decision-makers to continuously transform the transportation system in line with Government priorities. 
Note: Figure 2 was created by using System Dynamics software. A formula is embedded in each arrow that quantifies the relationship between the two quantities at the beginning and the end of the arrow respectively. The computer model enables the manager to graphically see the changes of various outputs by changing the inputs. Further analysis of the above falls outside the scope of this study.

It was stated that the systems approach is more concerned with the interaction between elements in a system than with the elements themselves. This is emphasised by Figure 2. Most of the elements in Figure 2 already exist; however, many of them currently do not interact with each other at all. This is illustrated by the large number of broken lines, which indicate interactions that do not yet exist. The main challenge for the implementation of the transportation decision-support system is to create these links. Once these links have been created, new data sources can be integrated to obtain more representative transportation decision-support figures. One of these is electronic vehicle identification, which is broken down into two elements, namely cell phone spotting and compulsory tags on vehicles (refer to the dotted oval labelled "New data sources" in Figure 2). The word "compulsory" was added as many advocates of electronic vehicle identification see this as the ultimate solution. This may still be a long legal battle, especially regarding personal privacy. In the interim there are many ways to achieve almost the same result voluntarily.

In the following section Figure 2 will be used as a framework to define the outstanding work elements of a project to implement a holistic transportation decision-support system.

\section{MAIN ELEMENTS OF THE TRANSPORTATION DECISION-SUPPORT SYSTEM}

\section{Introduction}

In this section the main elements of the transportation decision-support system are discussed. Please note the top-down sequence of defining the elements: first, the central computer and resulting management reports (the "why" of the transportation decisionsupport system), then the integration of existing data sources with the required algorithms and only then the new data sources. Most of these elements (and the links between them) can be identified in Figure 2.

\section{The central information base}

Firstly, a central database (with computing power) has to be created, to compile the various inputs and to combine them into an effectiveness figure for transportation as a whole. This is illustrated in Figure 3. 


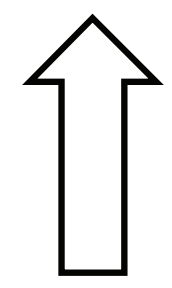

Focused, timely management

information to selected users
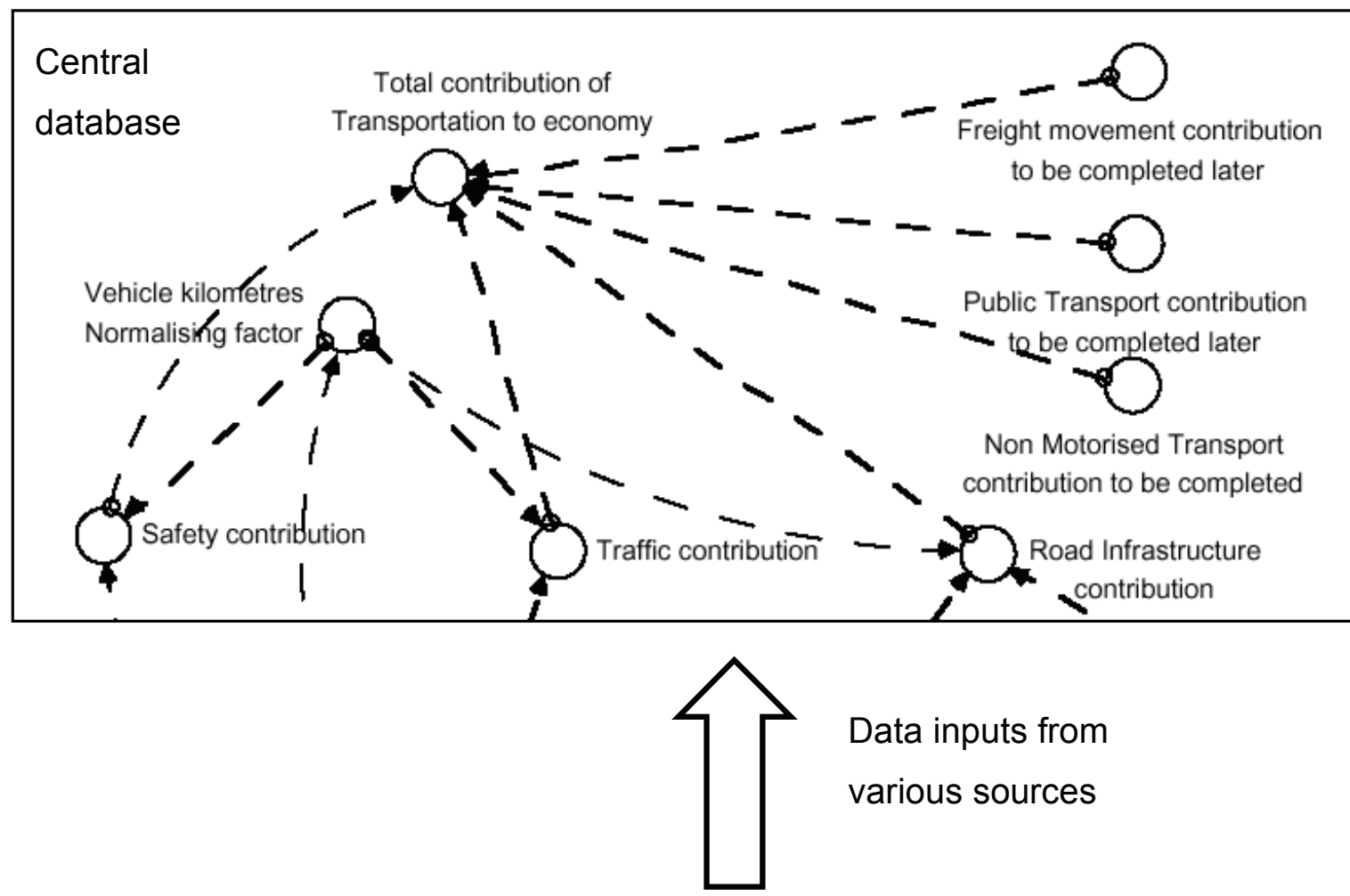

Data inputs from

various sources

Figure 3: Illustration of a central information base, integrating various information sources and processing this into focused management information

Figure 3 illustrates how the contribution of various applications should be developed within a central information base, from where they can be combined into a total effectiveness figure (only three applications are shown). A state-of-the-art desktop computer that is coupled to the Internet and to the internal Government computer networks should be adequate for this purpose. The term "information base" is used, as it also has to have computing power to transfer data into decision-making information.

\section{Management reports}

The above centralised computer system will create and distribute management information in the form of various reports as and when required by the various users. One of the most important management reports that must be developed is the executive report at Transport Branch level. Traditionally, traffic surveying in Gauteng was mainly perceived as the counting of vehicles. However, in this study the function is broadened to "transportation decision support" which includes the acquiring and processing of all information that is needed to measure, evaluate and improve transportation in Gauteng. 
Therefore, an executive transportation report has to include the following elements:

a. Feedback on the cost-effectiveness at top level

b. An indication of the improvement or "transformation" of the cost-effectiveness of transportation over time

c. An indication of the areas where improvements will have the biggest impact (i.e. exception reporting - such as hazardous locations and congestion hotspots)

d. The same has to be broken down into its lower-level components and distributed to the accountable parties for spontaneous corrective action (e.g. improvement of road maintenance or markings at hazardous locations).

A sample executive report that addresses the above dimensions is shown in Figure 4.

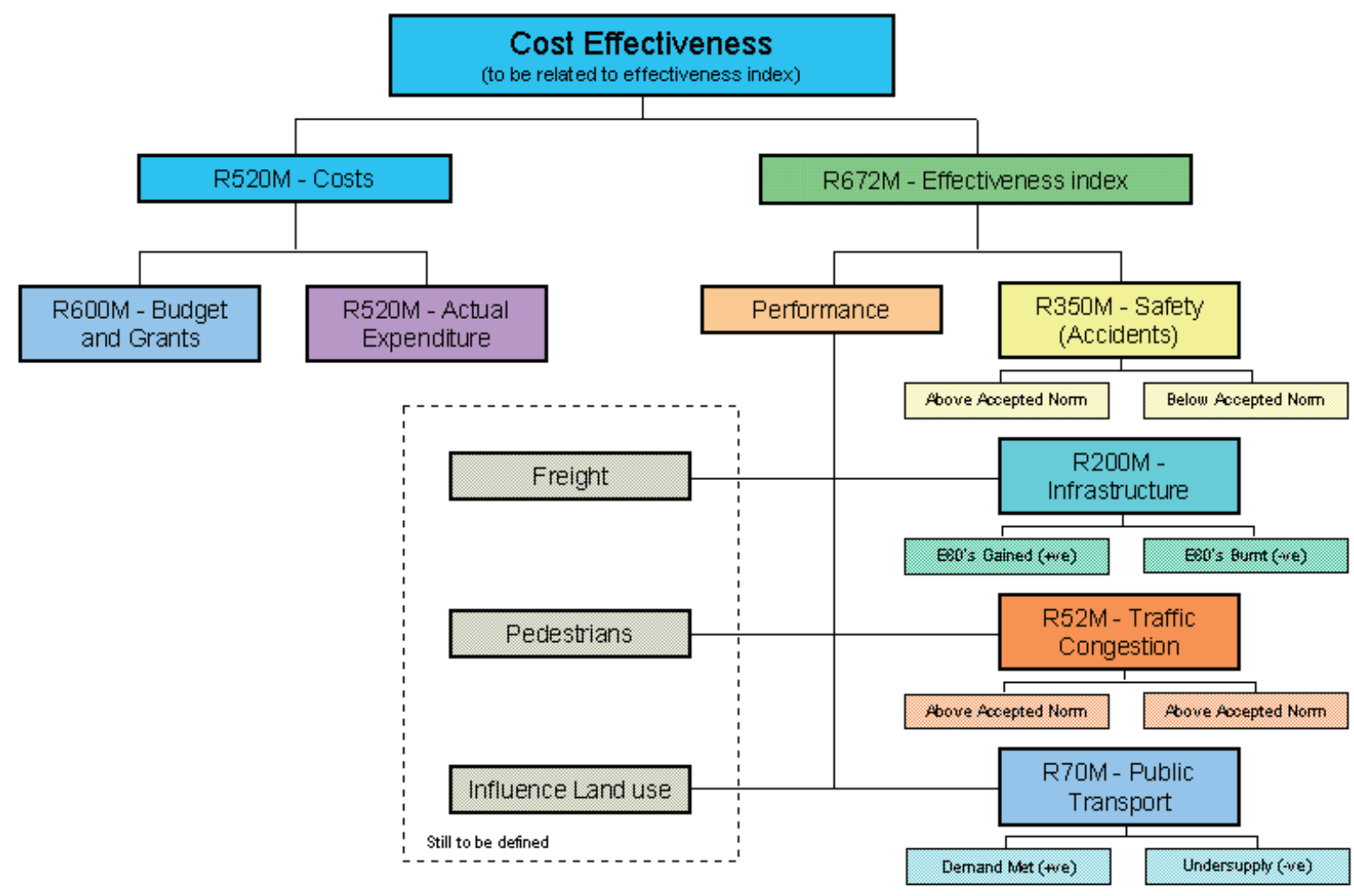

Figure 4.1: Cost-effectiveness of transportation (for demonstration purposes only) 
A Decision-Support System for Improving Road Transportation Performance in Gauteng, South Africa: Developing a Data Acquisitioning System

Report Period: 01/11/2002 to 31/10/2003

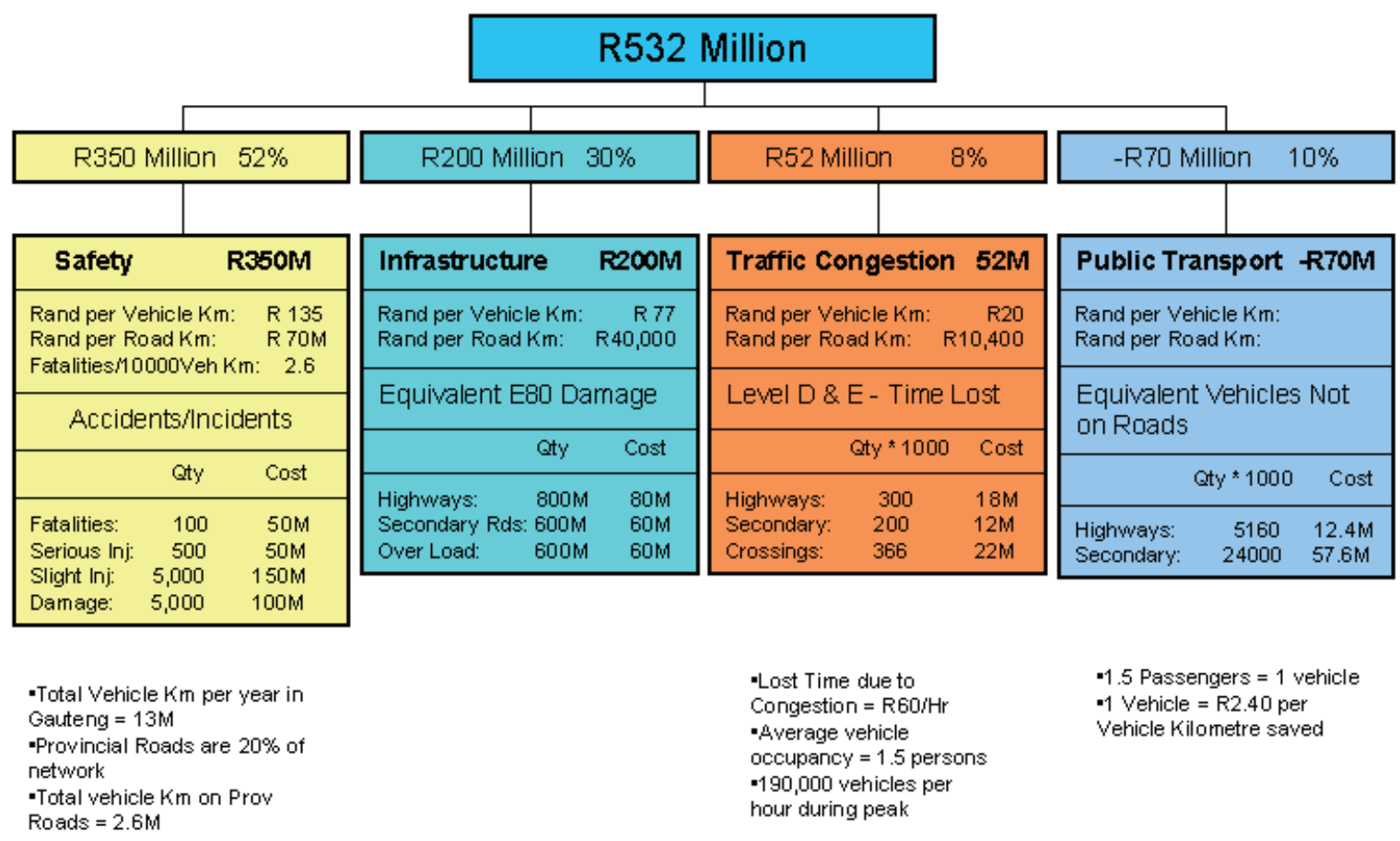

-Provincial roads in Gauteng = $5,000 \mathrm{Km}$

Figure 4.2: Effectiveness index

(for demonstration purposes only)

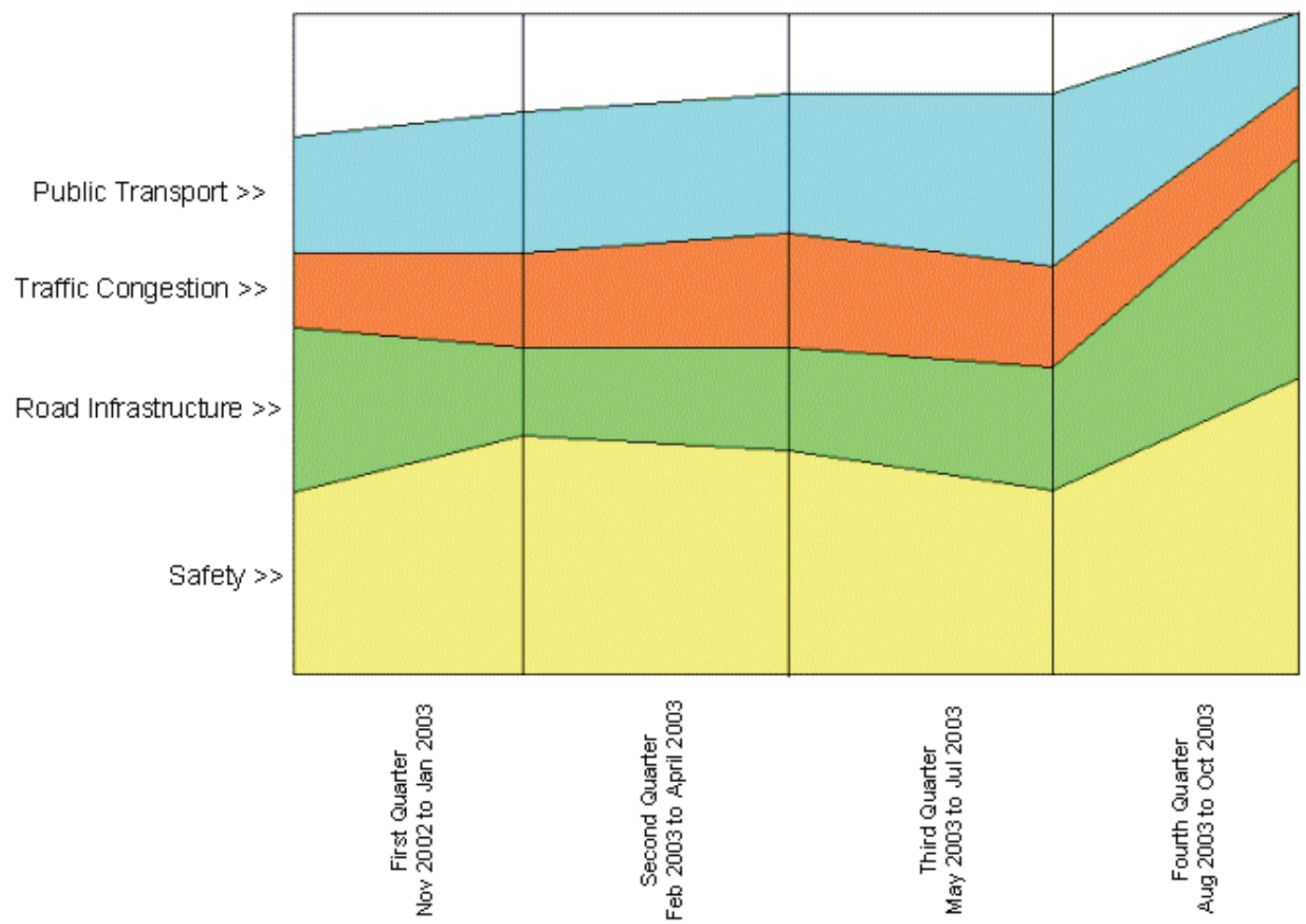

Figure 4.3: Effectiveness index trend

(for demonstration purposes only) 


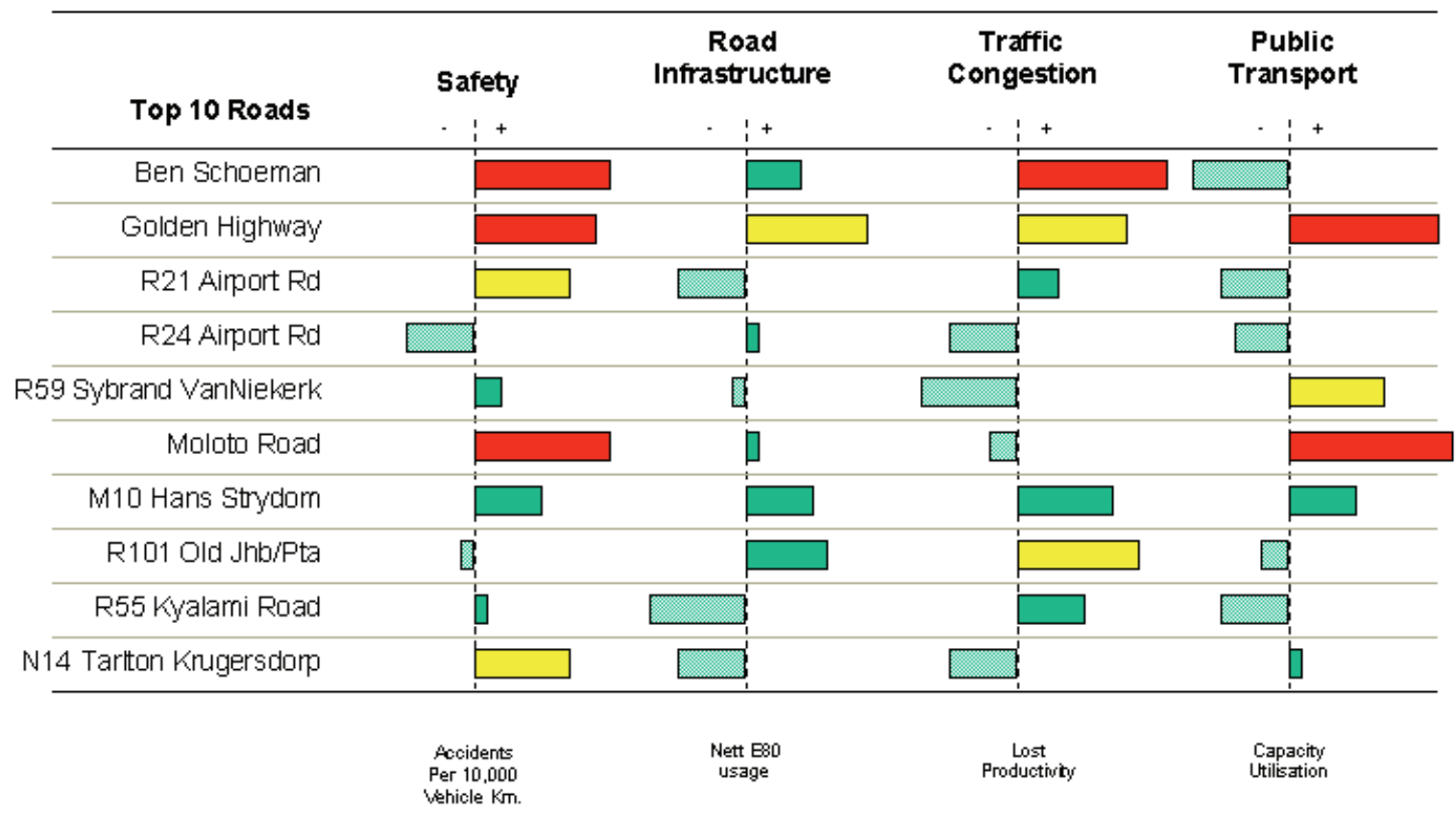

Figure 4.4: Exception report (for demonstration purposes only)

The report in Figure 4 starts with the big picture (as required by the systems approach) and gradually drills down:

Figure 4.1 gives an overview of the money spent and the performance achieved for this money. The performance in the effectiveness domain is shown in terms of the net value added over the reporting period for each application.

Figure 4.2 zooms in on the effectiveness domain, and supplies more detail on each element.

Figure 4.3 shows the effectiveness trends of all the applications or effectiveness indicators over a number of reporting periods.

Figure 4.4 gives a visual overview of the most critical exceptions for each application in the effectiveness domain.

\section{Linking system or network}

A linking system (or network) will be needed to obtain all information, process it, supply it to the central computer and distribute management reports. This is illustrated by the arrows in Figure 2. 


\section{Existing data sources}

The above management information has to be obtained from reliable data sources. There are currently many data sources within Gauteng that are not fully exploited or integrated for the purpose of transportation decision support. They include the following:

a. Municipal and national vehicle counting stations - Information from these databases should be integrated with the provincial database.

b. Municipal, national and private weigh bridges - Weigh bridges are currently mainly used for law enforcement. They can however also supplement the information base of traffic counts and freight movement.

c. Tollgates - Currently, tollgates are only used for revenue collection. They collect revenue based on the number of axles of vehicles. Accurate traffic counts and valuable estimates of freight movement can be obtained from this source, which could be extrapolated to other areas. Information from electronic tags (or E-tags) may also supply limited origindestination information.

These existing sources are shown towards the bottom of Figure 2. The full value of these databases can only be realised if their information is integrated into a central database accessible for all identified stakeholders. The focus may initially be on the Gauteng Transport Branch, expanding to the National Department of Transport and local authorities later.

To summarise: It should be possible to obtain a fair indication of the rate of improvement (or transformation) of transportation in Gauteng by only exploiting and integrating existing data sources. The initial focus of transportation decision support should therefore be to integrate all the above data sources into a database. This data should then be processed and distributed to each selected client, tailor-made to his or her specific needs.

\section{Algorithms, expansion factors and benchmarks}

Many of the elements in Figure 2 can be called "converters" as they convert data into more refined information that will eventually facilitate decision-making at various levels. An example is the conversion of axle loads into wear of road surface, determined by the equivalent 8 ton loads times distance in $\mathrm{km}$ or $[\{\mathrm{E}-80\} \times\{$ kilometres $\}]$. Eventually this has to be translated into the cost of damage to and the ageing of road infrastructure. To achieve this, algorithms are needed. Furthermore, the information has to be extrapolated to the whole road network, which needs expansion factors. Lastly, benchmarks are needed for performance evaluation. The implementation plan will therefore include the development of algorithms, expansion factors and benchmarks. 
In the following subsections the three new (or proposed) data sources in Figure 2 are discussed. They are electronic vehicle identification (EVI) by cell phone spotting and by pre-registered tags on vehicles as well as telephonic accident capturing.

\section{New data sources (not yet in existence)}

\section{Electronic vehicle identification by cell phone spotting}

In Figure 2, vehicle tags and cell phone spotting (or SIM-card spotting - to be technically correct) are the only data sources that make origin-destination information of vehicles and passengers possible. This type of information is important for proper transportation planning, and can also be used for other purposes, such as market research. In the past, this had to be obtained by means of labour-intensive questionnaires at limited frequencies. Current technology makes it possible to obtain the above information on a daily basis enabling the decision-maker to immediately pick up changing trends and cyclic behaviour. Electronic vehicle identification is therefore most important for transportation decision support. The full benefits can however only be obtained if it is part of an integrated system, such as the one illustrated in Figure 2.

It is known that many drivers using public roads have cell phones. By obtaining the positions (in terms of cell phone towers or "cells") from the cellular network suppliers, the movement of vehicles can be derived. The information obtained in such a way can also be of value to other stakeholders, such as market analysts. This again confirms the importance of systems thinking, where the "element" electronic vehicle identification also has other purposes than that of contributing to the transportation decision-support function alone.

\section{Electronic vehicle identification by pre-registered tags on vehicles}

Added benefits can be obtained by the spotting of pre-registered vehicles by means of active or passive identification tags (or transponders) on the vehicles. The spotting information is then transferred to a central database via a network of tag readers along the road network. As all these vehicles are pre-registered, each tag can be related to a vehicle type, his driver, and numerous other types of information of interest. The result is origindestination information as in the previous case, but with more information attached to it, such as vehicle type, demographics, etc. In contrast to cell phone spotting, the main part of the infrastructure for this system still has to be created and paid for.

It is proposed that the testing of the electronic vehicle identification concept be included in the implementation phase of the transportation decision-support system, by means of a pilot project on a voluntary basis.

In the above case, a user can determine the latest positions of his vehicle or fleet of vehicles, by means of controlled access to the database. This can add value to security and vehicle 
fleet management. It can also assist insurance companies with verifying claims. Many insurance companies already use tracking systems for this purpose.

\section{Telephonic capturing of relevant accident information}

Traditionally the Transport Branch had to rely on the National Accident Register (NAR) for accident information. This database uses information from police records as prime input source. As the same information base is used for prosecution, it has to be accurate and complete. The result is that the process may be delayed to obtain information that is not of prime importance to transportation. The need exists for a database that is more up to date, but only accurate enough to make statistical deductions possible. Only information relevant to transportation is necessary. Such a database can be maintained through telephonic datacapturing by various officials, including traffic officers and police officers. Furthermore, the exact position of the accident is currently often not available. This is of great importance when designing solutions for so-called accident spots. Cell phone spotting (discussed above) can assist in obtaining greater accuracy in this regard.

\section{Summary of system elements}

The section started with an overview or scope of the proposed integrated transportation decision-support system for Gauteng (Figure 2). From the above, the various elements were described, which form the basic deliverables for the implementation plan. They are as follows:

a. Central data and information base with reporting mechanism

b. Management reports

c. Integrating or linking system to enable data mining from data sources

d. Developing algorithms, expansion factors and benchmarks

e. Existing data sources

f. New (to be developed) data sources.

All the above elements need now to be packaged into an implementation plan or project. "Once the purpose/mission and objectives have been determined, the initial scope of the project needs to be defined. The precursor to this is establishing the project deliverables. The essential tool used to assist in the development of the project deliverables is the Deliverable Breakdown Structure (DBS)" (Comninos, 2000: Section 3.2, p 5). The above system elements form the basis of a deliverable breakdown structure for an implementation project.

\section{SUMMARY}

This research described how the systems approach can be applied to implement a holistic transportation decision-support system, which will measure transportation performance 
at the highest level and enable decision-making with respect to possible improvements. Gauteng Provincial Transport was used as a case study.

The research started by creating a framework of the process to be followed (Figure 1). Then a framework of the envisioned system with existing and new elements was created (Figure 2). This framework clearly illustrated the systems principle that the main challenge lies in the interfaces between elements, and not in the elements themselves, as many of the measuring elements already exist in Gauteng, but are not properly linked. Furthermore, a framework for management reports was proposed.

With the above as background, the deliverables for a project to implement the proposed data acquisitioning system were defined. First order indications are that such a project is feasible and affordable, and can be completed to such an extent that most of the advantages can be obtainable within two years (Arcus Gibb, 2004). A detailed project proposal falls outside the scope of the research.

\section{IMPLICATIONS FOR DECISION-MAKERS}

At the cost of merely combining existing data elements decision-makers will be able to establish and quantify the real need, by being able to prioritise and synergise between various transportation elements. This is not readily possible without integrated (combined) information.

\section{CONCLUSION}

By applying systems principles an affordable integrated transportation data acquisitioning system is possible.

\section{ACKNOWLEDGEMENTS}

This paper is based on research within the Gauteng Department of Public Transport, Roads and Words, which eventually led to a transportation surveying strategy, completed in 2004. 


\section{REFERENCES}

Ackoff, R.L. 1981. Creating the corporate future, John Wiley \& Sons Inc., New York.

AFReC 2002. Financial Management Module 1. Course presented for the Gauteng Management Development Programme, Benoni. September.

Anon 2005a. The cost of logistics. Transport World Africa, 3(2): 21. March/April.

Arcus Gibb. 2004. Traffic surveying strategy for the Gauteng Provincial Government. Report number J23104A100/01. Study directed by Arcus Gibb under sponsorship of the Gauteng Department of Public Transport Roads and Works. January.

Backeberg, G.H. 2005. A systems approach to transportation surveying in Gauteng, South Africa. Southern African Business Review, 9(1): 21-31. April.

Brits, A., Shahia, M., Vorster, F.N. \& Barendrecht, J.W. 1994. Transport economics (study guide). University of South Africa, Pretoria.

Comninos, D. 2000. Project Management Masterclass - course presented by Comninos, Johannesburg. October.

CSIR \& Spoornet 2004. The first state of logistics survey for South Africa. Sponsored by CSIR Centre for Logistics and Decision Support and Spoornet. Available: http://www.csir. co.za/plsql/pTI0002/PTL0002_PGE011_PUBLICATION_LST. Consulted 29 July 2005.

Gauteng Department of Public Transport, Roads and Works, 2001. Annual Report 2000/1. Available: http://www.gpg.gov.za/docs/reports/annuals01/plans.html. Consulted 27 June 2005.

Gauteng Department of Public Transport, Roads and Works 2002. Annual Report. Johannesburg.

Gauteng Department of Public Transport, Roads and Works 2003. Provincial land transport framework for Gauteng, 2002-2007. Johannesburg. January.

Gauteng Department of Public Transport, Roads and Works 2003b. Strategic plan 20032006. Johannesburg. 11 March. 
Gharajedaghi, J. 1999. Systems thinking: Managing chaos and complexity, ButterworthHeinemann, Boston.

Greenwood, B \& Denton, R 2003. Developing a safety management system for road authorities, Safety management systems project: conference paper. Available: http://www. Itsa.govt.nz/roads/sms/conference-paper.html. Consulted 30 November 2004.

Kast, F.E. \& Rosenzweig, E. 1974. Organisation and management - a systems approach. New York: McGraw Hill. 655 p.

Mallach, E.G. 1994. Understanding decision support systems and expert systems. New York: McGraw-Hill.

National Government of South Africa 1999. Public Finance Management Act, Act 1 of 1999 as amended by Public Finance Management Amendment Act, Act 29 of 1999. Government Gazette. No. 19814. 2 March 1999. Cape Town.

Poggiolini, D. 2004. EVI being mooted for South Africa. Transport World Africa, 2(6): 16. Sept/Oct.

Poggiolini, D. 2005. Freight logistics strategy progress. Transport World Africa, 3(1): 15-17. Jan/Feb.

Rule, S. 2004. Motivations behind voting behaviour in South Africa. Election Synopsis 12: 8-20. Available: http://www.hsrc.ac.za/media/2004/4/20040405.pdf Consulted 4 July 2004.

Sparrius, A.D. 2005. Project Management Masterclass - course presented by Sparrius, Johannesburg. May.

Swanevelder, J.J. 2005. Performance measures (ratios) in the evaluation of financial and other results of municipalities: revisited. Southern African Business Review, 9(1): 66-77. April.

Turban, E. \& Aronson J.E. 1998. Decision support systems and intelligent systems; fifth edition. New Jersey. Prentice-Hall, Inc. 